\title{
PARCERIAS PÚBLICO-PRIVADAS NAS POLÍTICAS SOCIAIS O caso das freguesias da Área Metropolitana de Lisboa $(1993-1997)^{1}$
}

\author{
Carlos Mendes Pauleta ${ }^{2}$
}

\begin{abstract}
Resumo - A actual fase do desenvolvimento capitalista é caracterizada por uma centralização administrativa com o Estado-Nação a perder poderes para instâncias supranacionais. Todavia, tem ocorrido a descentralização de algumas funções, particularmente de carácter social, para os níveis locais da Administração Pública como o prova a crescente actividade das freguesias. Esta nova situação manifesta-se no incremento da actividade social das freguesias que promovem iniciativas próprias, actuam em parceria ou subsidiam instituições públicas e particulares que actuam à escala local, sendo as políticas sociais que adoptam influenciadas por diversos factores, dos quais destacamos a estrutura do território e o partido político dominante nos órgãos da autarquia.
\end{abstract}

Palavras-chave: freguesias, descentralização administrativa, políticas sociais, parceria.

Abstract - Public-PRivate PARTNerships in Social POlicies. The CASE OF the PARISHES IN THE LisBon METROPOLITAN AREA - Capitalist development is currently characterised by an administrative centralisation with the Nation-State losing power to supranational authorities. However, some functions have been decentralised, specially the ones of a social character, to local levels of Public Administration, as can be seen by the increase of parish activities, which develop their own plans, act in partnership or subsidise public and private institutions at a local level. The social policies that the parishes adopt are influenced by several factors, among which we detect the structure of the territory and the dominating political party within the local government council.

Key-words: parish, administration decentralisation, social policies, partnership.

1 Este artigo beneficiou da informação recolhida no âmbito do Projecto de Investigação n. ${ }^{\circ}$ SSPS/C/PCL/2608/96 - Poder Local e Politicas Sociais: subsidiariedade e parceria na segurança social, 1996 - 1998, financiado pela JNICT e pelo MSSS e coordenado pelo Prof. Doutor Carlos Nunes Silva, e da informação que suporta a análise efectuada na dissertação de mestrado apresentada à Faculdade de Letras de Lisboa sob o título "As Políticas Sociais das Freguesias na Área Metropolitana de Lisboa (1993-1997)».

2 Mestre em Geografia Humana e Planeamento Regional e Local. E-mail: rocha.pauleta@mail.telepac.pt. 


\section{INTRODUÇÃO}

A Constituição da República Portuguesa, aprovada em 1976, afirma que «a organização democrática do Estado compreende a existência de autarquias locais» identificando-as como "pessoas colectivas territoriais dotadas de órgãos representativos, que visam a prossecução de interesses próprios das populações respectivas» e são, no continente, «as freguesias, os municípios e as regiões administrativas» ${ }^{3}$.

As freguesias são entidades administrativas inframunicipais sem paralelo nos restantes países europeus, nomeadamente, no que respeita à legitimidade que lhe advém do facto de terem órgãos eleitos por sufrágio universal e directo e de disporem de um conjunto de atribuições próprias. Estas entidades locais gozam de autonomia administrativa e financeira e, apesar de terem uma reduzida dimensão e de disporem de escassos meios financeiros, têm vindo a aumentar a sua capacidade de intervenção.

Neste artigo, procuramos esclarecer se existe uma tendência para que algumas funções sociais, que têm competido ao Estado, passem para a responsabilidade do poder local, nomeadamente das freguesias, e de organizações da sociedade civil, ou seja, se a actual fase do desenvolvimento capitalista implica uma organização administrativa mais descentralizada ou mais centralizada do que aquela que vigorou durante a vigência do regime de acumulação fordista.

Analisamos, também, as políticas sociais que adoptam e as formas de as levar à prática, tomando como caso de estudo a Área Metropolitana de Lisboa (AML) e tendo em consideração que muitas das actividades que desenvolvem são executadas em conjunto com outras entidades locais, procuramos identificar os parceiros das freguesias na regulação social à escala local.

Partimos do princípio de que: (a) o território influencia e condiciona a intervenção das freguesias na regulação local; (b) a actual fase do desenvolvimento capitalista tende para uma maior descentralização da Administração Pública e a regulação local, ao nível da freguesia, incorpora elementos da sociedade civil; (c) os factores locais e a proximidade das populações influenciam mais a actividade dos eleitos do que a sua origem ideológica. Todavia, a influência partidária condiciona as opções de gestão das freguesias e a escolha dos parceiros sociais.

Ao longo do presente artigo considerámos, ainda, que as freguesias exercem o poder e a autoridade numa sociedade instalada num território, contribuem para regular um determinado regime de acumulação ao nível local, permitem a intervenção e participação das populações na administração e na gestão do território e, finalmente, participam na resolução de problemas gerais da sociedade em função da correlação de forças que a cada momento se estabelecem, do nível de descentralização existente e dos meios financeiros de que dispõem.

3 Constituição da República Portuguesa, Art. ${ }^{\circ}$ s $235 .^{\circ}$ e 236. ${ }^{\circ}, 4^{a}$ revisão, 1997: 216 e 217. 
Partimos da hipótese de que as políticas e a acção das freguesias dependem do grau de autonomia com que exercem a sua actividade, dos recursos financeiros de que dispõem, do nível e das características da descentralização, do partido político dominante e das características sócio-geográficas do território (SILVA, 1994: 9), bem como das relações que se estabelecem, por um lado, entre aquelas, as câmaras e os órgãos do Estado e, por outro lado, nas comunidades locais, entre as diversas classes, camadas sociais e sectores de actividade que as constituem, tomados isoladamente ou através das organizações que as representam.

Em suma, considerámos que o funcionamento das freguesias é regulado por três formas estruturais principais, que condicionam as relações sociais fundamentais e dão uma expressão material contingente aos conflitos sociais (BENKO, 1996: 112) ao nível local, que identificámos como sendo as condições sóciogeográficas do território, os recursos financeiros das freguesias (SILVA, 1994: 9), e as relações que, a cada momento, se estabelecem entre a população, as câmaras municipais e os órgãos do poder central.

\section{Tendências recentes do capitalismo - a emergência de um novo modelo de desenvolvimento}

Com o fim da II Guerra Mundial, a economia dos países capitalistas mais desenvolvidos iniciou um período de crescimento estável que se prolongou até finais dos anos 60. A partir de então começou a dar mostras de esgotamento (DUNFORD, 1994: 145 e BENKo, 1996: 19), iniciando-se uma crise que o primeiro choque petrolífero de 1973 tornou evidente. Todavia, o seu carácter estrutural só mais tarde foi revelado (BOYER, 1994: 121).

Hoje, diversos autores relacionam esta crise com o esgotamento do modelo de desenvolvimento que ficou conhecido por fordismo, assente num regime de acumulação de capital intensivo, caracterizado por um tipo de organização da produção que privilegia a divisão técnico-científica do trabalho (TAYLORISTA que distingue as fases de concepção e de fabricação), na procura de economias de escala e numa repartição dos rendimentos assente na negociação colectiva que envolve o Estado, os sindicatos e as associações patronais, no alargamento do consumo social, e num modo de regulação que garante a redistribuição dos ganhos de produtividade através de uma legislação social, de convenções colectivas e do Estado-Providência (BENKo, 1996: 92 e 93 e BOYER, 1994: 124 a 127).

Entretanto, com o esgotamento deste regime de acumulação começa a emergir outro caracterizado por uma maior adaptabilidade da produção às necessidades do consumo, com maior especialização produtiva, assente em empresas de menor dimensão organizadas em rede, com contratos de trabalho mais flexíveis e em que a relação salarial é menos rígida e muitas vezes dependente de três factores: garantia de uma retribuição mínima, mérito próprio e 
resultados da empresa (BENKo, 1996: 122). Há, ainda, a considerar, a diminuição do papel regulador do Estado e o aparecimento ou o reforço de novos agentes que intervêm na regulação em todas as escalas, desde a local à internacional.

O novo modelo produtivo, devido a algumas das suas características maior aptidão dos trabalhadores para controlarem diversos segmentos de um mesmo processo produtivo, maior flexibilidade dos contratos de trabalho, melhor ajuste salarial às necessidades da produção e possibilidade das empresas se subtraírem a encargos sociais e fiscais (BENKo, 1996: 30 a 32)-tem contribuído para o agravamento de diversos problemas sociais, dos quais salientamos o aumento do desemprego, a intensificação dos ritmos de trabalho, o alargamento da jornada de trabalho, o aumento das assimetrias sociais e a exclusão social.

\section{Consequências sociais da globalização e o papel das freguesias}

Com a emergência do novo regime de acumulação são postas em causa as políticas económicas intervencionistas, nas quais o Estado assume um papel directo na economia, e adoptadas políticas económicas neoliberais. O mercado foi eleito como regulador natural de toda a actividade económica, privilegiou-se a iniciativa privada e o capitalismo concorrencial (DUNFORD, 1994: 145), e combateram-se todas as manifestações de proteccionismo económico e o Estado-Providência.

Os defensores do Estado mínimo, que passaram a estar na ordem do dia, sustentam que o ponto de equilíbrio dos mercados financeiros, de capitais, de trabalho e a protecção do ambiente só se atingem com regulamentações mínimas e propõem «a adaptação das regulamentações nacionais, incluindo em especial a fiscalidade e as regulamentações do trabalho, às exigências da concorrência provocadas pela globalização» (LOPEs, 1997: 34).

A privatização, a liberalização e a desregulamentação contribuíram para acelerar a internacionalização da economia, pôr em causa a existência do mercado nacional, que constitui o fundamento do Estado-Nação (GRUPO DE LisBOA, 1994: 49), acelerar a competição económica, flexibilizar o emprego, com reflexo na sua precarização e no aumento do desemprego e, pôr em causa o Estado-Providência, com todas as consequências sociais daí decorrentes.

A internacionalização da economia, e a inovação das comunicações, das telecomunicações e dos transportes, reduziu extraordinariamente as distâncias que separam os diversos povos do mundo e contribuiu para o aumento da intensidade dos fluxos financeiros, de pessoas, bens e serviços que se estabelecem entre os diversos países, dando origem a uma nova configuração mundial, a globalização.

Do ponto de vista social, esta nova situação é, simultaneamente, integradora e fonte de exclusão, em virtude de gerar novas oportunidades económicas 
ao permitir investir em qualquer ponto do globo ou atrair investimentos e porque deixa de fora importantes parcelas do território e os seus habitantes, abandonados à sua sorte, ou porque não permite o acesso generalizado da população, mesmo daquela que vive nas áreas e regióes mais desenvolvidas, às novas tecnologias (BORJA e CASTELLS, 1997: 184).

A competição económica, que se desenvolve à escala nacional e, sobretudo, mundial, está a acelerar a tendência para a «apropriação da força de trabalho pelo capital em escala planetária» e traduz-se no «desenvolvimento do processo de concentração e centralização do capital «global»» (BENKo, 1996: 45).

Entretanto, a qualidade de vida dos trabalhadores assalariados degrada-se na proporção directa do aumento dos índices de exploração que são consequência dos maiores ritmos de trabalho impostos, do aumento da jornada de trabalho, da exclusão precoce dos trabalhadores incapazes de acompanhar as novas performances, nomeadamente os mais idosos mas ainda novos para se reformarem, e da utilização de subtis e sufocantes pressóes com o objectivo de obter a sua total disponibilidade para satisfazer as necessidades do empregador (Kovács e CASTILLO, 1998: 16).

O processo de reestruturação económica, que se encontra em curso, suscita sérias preocupações pelos inconvenientes sociais que está a produzir (aumento do desemprego, da pobreza, das assimetrias, das situações de exclusão) tanto mais que «a globalização ocorre numa altura em que o envelhecimento das populações dos países ocidentais implica a necessidade de uma grande actividade redistributiva entre as diversas gerações da sociedade» (AMARAL, 1997: 40).

Como se pode ver, a situação não é animadora, tanto mais que o agravamento das condições de vida, da pobreza, das assimetrias sociais, são a maior fonte de alimentação da delinquência e da revolta a que geralmente os Estados respondem "com fúteis medidas repressivas», com a "acção da polícia», quando a "solução mais humana, e também, muito possivelmente, a mais barata, passará por acabar com a pobreza que induz à desordem social» (GALBRAITH, 1997: 49 e 50).

Torna-se, por isso, necessário promover as medidas e desenvolver as acções que contribuam para aumentar a autonomia das populações através do fortalecimento das redes sociais internas dos residentes dos bairros mais carenciados, encorajando a formação e organização de grupos (FRIEDMANN, 1996: 173) que se interessem pelos problemas locais, associações regionais, de imigrantes, da juventude, desportivas, de mulheres, ecologistas, cooperativas, estimulando a sua participação social e política e garantir a descentralização do poder que é uma condição essencial para permitir a participação das populações na construção do seu próprio futuro.

No caso português, parte dessa descentralização deve ser feita para as freguesias, que estão em condições de assumir algumas funções, que hoje são da responsabilidade do Governo ou dos municípios e podem ser por si exercidas com vantagens sociais e económicas. 
As freguesias estão bem posicionadas para se relacionarem com as populações, identificarem as suas necessidades básicas e contribuírem para a resolução de muitos problemas sociais e, ainda, para estimularem a organização e a participação política das populações. Acresce que a curta distância que separa as freguesias das populações permite eliminar circuitos, que favorecem a burocracia, e facilita o controlo social sobre os órgãos, tornando-os mais eficientes.

\section{AS POLÍTICAS SOCIAIS DAS FREGUESIAS}

Não é fácil estabelecer a fronteira entre o que pertence ou não ao domínio social na intervenção das freguesias. A simples passagem de um atestado é um acto eminentemente social, uma vez que, quase sempre, é solicitado por idosos de fracos recursos económicos e destina-se a obter descontos no pagamento das tarifas do telefone, do abastecimento de água ou da energia eléctrica.

As freguesias, apesar de não disporem de meios para acompanharem a maioria dos problemas sociais, procuram responder às solicitações que lhes são feitas, solucionando as situações mais graves. Dedicam-se, sobretudo, a acções de animação relacionadas com a cultura, tempos livres e desportos, os idosos, a infância e juventude e, em menor escala, a saúde, que têm, sem dúvida, grande importância na prevenção de muitos problemas sociais.

Por isso, torna-se importante inventariar as acções que mais frequentemente são realizadas pelas freguesias e os equipamentos de que dispõem para desenvolverem as políticas sociais que adoptam.

\section{Desporto, cultura e tempos livres}

As freguesias não têm muitos equipamentos desportivos, dado o custo que a sua construção e manutenção implicam. Na sua falta recorrem aos ginásios e polidesportivos que são propriedade das câmaras, escolas e colectividades ou estimulam a prática de modalidades que não necessitam de recintos fechados.

As actividades desportivas desenvolvidas pelas freguesias destinam-se, sobretudo, às crianças e jovens. Muitas vezes encontram-se englobadas em iniciativas comemorativas de datas com significado para as autarquias ou para sectores específicos da população (25 de Abril, Dia do Ambiente, Dia da Criança, etc.).

Há freguesias que desenvolvem acções orientadas por projectos para os quais são mobilizados outros agentes locais. É o caso das escolas de formação desportiva que funcionam no Pragal (Almada) e nos Prazeres (Lisboa), envolvendo a autarquia, as escolas do $1 .^{\circ}$ ciclo do ensino básico e associações desportivas locais proporcionando a prática de diversas modalidades.

As freguesias da AML dispõem de um razoável número de equipamentos culturais (45 freguesias têm bibliotecas; 15 têm auditórios; 17, galerias de arte; 4, museus; 6 , centros de documentação; 4, videotecas; 1 , bedêteca e 4, centros 
culturais) ${ }^{4}$ e promovem, a partir destes equipamentos, múltiplas iniciativas e acções de carácter cultural.

As expressões culturais e as iniciativas promovidas procuram responder aos gostos e interesses das populações locais. Os apoios aos ranchos folclóricos são mais frequentes nas freguesias com características mais rurais ou onde vivem núcleos populacionais oriundos daquelas regiões (Aveiras de Cima, Aveiras de Baixo - Azambuja, Coina-Barreiro, Falagueira - Amadora e Alverca - Vila Franca de Xira). Outras promovem festas tradicionais (Rio de Mouro - Sintra, Alcântara, Charneca-Lisboa). Mas, também, apoiam a música criando ou patrocinando escolas com esse objectivo (Malveira - Mafra, Seixal e Aveiras de Cima) e o teatro (Rio de Mouro, Santa Catarina, Santa Engrácia, Prazeres e Pena-Lisboa) ou organizam concursos de poesia (Cascais) e jogos florais (Ameixoeira - Lisboa).

\section{Saúde}

A saúde é o sector do domínio social no qual as freguesias têm menor possibilidade de intervir. Os custos dos equipamentos e da sua manutenção, associados aos elevados vencimentos dos técnicos tornam quase impossível a sua intervenção.

Mesmo assim, algumas freguesias procuram preencher as lacunas do Estado na oferta e prestação de serviços de saúde. Seis freguesias têm postos médicos abertos. Mas, a prestação de serviços não é a única forma que as freguesias utilizam para satisfazer as necessidades de cuidados médicos da população. Por vezes, financiam o Estado com a oferta de terrenos ou instalações para a construção ou funcionamento de centros de saúde. Para ultrapassar a exiguidade de recursos, outras freguesias procuram parceiros para resolver vários problemas do âmbito social e colectivo. Santa Catarina (Lisboa) celebrou um protocolo com os bombeiros para o transporte ambulatório, Aldeia de Paio Pires (Seixal) tem um protocolo com a câmara municipal, o centro de saúde, uma Instituição Particular de Solidariedade Social (IPSS) e uma associação de idosos, procurando potenciar as capacidades de cada uma das organizações para o acompanhamento dos idosos da freguesia; várias freguesias têm acordos celebrados com centros de saúde com o objectivo de organizarem acções de informação, com vista à prevenção de doenças e campanhas de vacinação que decorrem junto das escolas.

A actividade das freguesias no âmbito da saúde, tal como acontece em outros domínios da intervenção social, contempla com subsídios algumas instituições. Acresce, ainda, que há freguesias que atribuem, embora excepcio-

4 Dados extraídos do inquérito realizado no âmbito do Projecto de Investigação atrás referido (Poder Local e Políticas Sociais: subsidiariedade e parceria na segurança social), ao qual responderam 179 freguesias de todos os municípios da AML, onde vivem 86,5 \% dos seus habitantes. 
nalmente, subsídios a pessoas carenciadas para a compra de medicamentos (Corroios - Seixal e Rio de Mouro - Sintra).

\section{Infância e juventude}

No que respeita à infância e juventude, a maior parte das freguesias da AML têm como objectivo proporcionar as condições necessárias ao desenvolvimento equilibrado e integral das crianças e dos jovens. Também neste domínio procuram colmatar as lacunas, que o Estado não consegue preencher, pondo em funcionamento alguns equipamentos.

Atendendo aos fracos recursos financeiros de que as freguesias dispóem e aos elevados custos de alguns equipamentos e, particularmente, aos recursos necessários para o seu funcionamento, é de salientar que 18 freguesias têm actividades de tempos livres (ATL's), 11 têm parques infantis, 10 dispõem de ludotecas e uma de jardim de infância.

Mas, como as freguesias já há muito se aperceberam de que sozinhas não são capazes de resolver muitos dos problemas sociais que afectam as populações mais carenciadas, juntam-se a outras instituições com o objectivo de pôr em funcionamento mais equipamentos.

Em parcerias, formalizadas ou não, 13 freguesias participam na gestão de creches, 20 na administração de jardins de infância e 20 de ATL's. Mas, a intervenção mais frequente faz-se através da atribuição de subsídios às instituições, que dispõem de equipamentos.

A intervenção das freguesias nas áreas da infância e juventude dedica grande atenção às acções de animação, entre as quais se destacam a organização de jogos e festas, visitas e sessões culturais e passeios que organizam isoladamente ou em conjunto com outras instituições, nomeadamente escolas. Organizam, também, férias para as crianças mais carenciadas e a ocupação de tempos livres.

\section{Idosos}

Os idosos não constituem um estrato social homogéneo. Aliás, o mesmo acontece com a infância e a juventude. Com efeito, se há problemas que são comuns à generalidade dos cidadãos dos estratos etários mais elevados outros dependem de vários factores tais como o regime de segurança social em que se integram, as relações que mantiveram com a segurança social enquanto cidadãos no activo, a existência de rendimentos próprios para além dos provenientes das pensões de reforma, as características do meio, mais rural ou urbano, com maiores ou menores tradições associativas, em que se encontram inseridos.

O regime de segurança social, os anos de contribuição, a existência de rendimentos que complementem as reformas determinam a existência de diferentes capacidades para enfrentar os problemas da velhice. Por outro lado, o 
meio em que cada um se insere determina a existência e a intensidade dos laços de solidariedade que são extraordinariamente importantes e que têm reflexos nas condições de vida dos mais idosos. Nos meios rurais ou nos bairros urbanos tradicionais a inserção social do idoso está facilitada quando comparada com o isolamento oferecido pelos meios urbanos de génese recente. Esta diversidade de situações conduz a procuras diferentes que exigem respostas distintas.

Apesar dos elevados custos de manutenção e funcionamento, as freguesias da AML têm e gerem 7 centros de dia, 7 centros de convívio e 2 centros comunitários e participam, em parceria, através da cedência de instalações, em 15 centros de dia e outros tantos de convívio, 3 lares, uma residência definitiva e um centro comunitário.

A contribuição das freguesias para o funcionamento dos equipamentos para idosos é frequente através de subsídios. Com efeito, 90 freguesias (50,3\% das inquiridas) subsidiam centros de dia, $70(39,1 \%)$ contribuem com donativos para o funcionamento de centros de convívio e 53 (29,6 \%) dão subsídios para lares de idosos.

As acções desenvolvidas pelas freguesias são direccionadas para a animação e o convívio deste estrato da população. Normalmente, a sua actividade não tem como objectivo a satisfação de necessidades individuais (apoio domiciliário, higiene pessoal, limpeza de habitações, tratamento de roupas ou preparação de refeições) ${ }^{5}$ orientando-se, sobretudo, para acções colectivas (fornecimento de apoios aos centros de dia e a bares, alfabetização, colónias de férias, actividades físicas). Todavia, mostram grande disponibilidade para apoiar as instituições que se dedicam a prestar aqueles serviços através da atribuição de subsídios ou da celebração de parcerias.

\section{MODOS DE INTERVENÇÃO E PARCERIAS NAS POLÍTICAS SOCIAIS}

Procuraremos, de seguida, identificar os modos de intervenção das freguesias, no que respeita às políticas sociais, e os parceiros aos quais se associam, bem como analisar as relações que se estabelecem entre aquelas e as organizações de carácter social, que actuam no seu espaço geográfico.

Frequentemente, as freguesias desenvolvem acções com outras organizações da sociedade civil. A gestão dos equipamentos sociais também é muitas vezes efectuada em parceria. Importa, por isso, saber: (a) quem são essas organizações; (b) em que medida participam na regulação do território à escala local; (c) se a orientação político-partidária dos eleitos locais condiciona a

5 O que não impede algumas freguesias de prestarem estes serviços, como é o caso de Alcabideche. 
actuação das freguesias e o modo como se relacionam com as instituições de carácter social, que são suas potenciais parceiras.

\section{Modos de intervenção das freguesias}

A falta de meios das freguesias, as relações que mantêm com a Câmara Municipal, a estrutura etária, as características sociais da população, as tradições associativas locais e mesmo a orientação política dos eleitos influen-

e condicionam o seu modo de actuação.

No plano social, a actuação das freguesias processa-se segundo uma de três modalidades: promovendo acções e iniciativas ou gerindo equipamentos sociais próprios, associando-se a outras instituições em parcerias ou atribuindo subsídios, muitas vezes na base de projectos concretos, às diversas organizações que actuam na área da freguesia com objectivos sociais. Em alguns casos, combinam algumas ou todas as modalidades de intervenção atrás enunciadas.

As freguesias inquiridas intervêm em 566 equipamentos, estando a maioria deles relacionados com a cultura e o desporto (298): 165 são equipamentos para a infância ou a juventude, 91 para os idosos e apenas 12 se destinam à saúde (Quadro I).

QUADRO I - Intervenção das freguesias nos equipamentos sociais segundo o tipo de participação e o partido político do presidente, por sector social

TABLE I-Parish participation in social amenities according to type of participation and the president's political party, per social sector

\begin{tabular}{|c|c|c|c|c|c|c|c|c|c|c|c|c|c|c|c|c|c|c|c|c|c|}
\hline & \multicolumn{4}{|c|}{ Idosos } & \multicolumn{4}{|c|}{ Infância e Juventude } & \multicolumn{4}{|c|}{ Saúde } & \multicolumn{4}{|c|}{ Desporto e Cultura } & \multicolumn{4}{|c|}{ Total } \\
\hline & & Pro & Par & Sub & Tot & Pro & Par & Sub & Tot & Pro & Par & Sub & Tot & Pro & Par & Sub & Tot & Pro & Par & Sub & Tot \\
\hline \multirow[t]{2}{*}{$\mathrm{CDU}$} & Equipam. & 8 & 23 & 14 & 45 & 15 & 35 & 43 & 93 & 0 & 1 & 1 & 2 & 64 & 51 & 48 & 163 & 87 & 110 & 106 & 303 \\
\hline & $\%$ & 17.8 & 51.1 & 31.1 & & 16.1 & 37.6 & 46.2 & & 0.0 & 50.0 & 50.0 & & 39.3 & 31.3 & 29.4 & & 28.7 & 36.3 & 35,0 & \\
\hline \multirow[t]{2}{*}{ PS } & Equipam. & 10 & 20 & 12 & 42 & 19 & 19 & 20 & 58 & 6 & 3 & 0 & 9 & 49 & 24 & 34 & 107 & 84 & 66 & 66 & 216 \\
\hline & $\%$ & 23.8 & 47.6 & 28.6 & & 32.8 & 32.8 & 34.5 & & 66.7 & 33.3 & 0.0 & & 45.8 & 22.4 & 31.8 & & 38.8 & 30.6 & 30.6 & \\
\hline \multirow[t]{2}{*}{$\begin{array}{l}\text { PSD } \\
\end{array}$} & Equipam. & 2 & 1 & 1 & 4 & 5 & 4 & 5 & 14 & 1 & 0 & 0 & 1 & 11 & 4 & 13 & 28 & 19 & 9 & 19 & 47 \\
\hline & & 50.0 & 25.0 & 25.0 & & 35.7 & 28.6 & 35.7 & & 100 & 0.0 & 0.0 & & 39.3 & 14.3 & 46.4 & & 40.4 & 19.1 & 40.4 & \\
\hline \multirow[t]{2}{*}{ Total } & Equipam. & 20 & 44 & 27 & 91 & 39 & 58 & 68 & 165 & 7 & 4 & 1 & 12 & 124 & 79 & 95 & 298 & 190 & 185 & 191 & 566 \\
\hline & $\%$ & 22.0 & 48.4 & 29.7 & & 23.6 & 35.2 & 41.2 & & 58.3 & 33.3 & 8.3 & & 41.6 & 26.5 & 31.9 & & 33.6 & 32.7 & 33.7 & \\
\hline
\end{tabular}

(Pro = único promotor; Par = intervenção em parceria; Sub = através de subsídio; Tot $=$ total)

Fonte: Inquérito realizado às freguesias no âmbito do Projecto de Investigação n. ${ }^{\circ}$ SSPS/C/PCL/2608/96 - Poder Local e Políticas Sociais: subsidiariedade e parceria na segurança social, 1996-1998 (Silva, 1998)

A intervenção junto dos equipamentos para idosos é maioritariamente feita 
em parceria $(48,4 \%)$ e o subsídio é utilizado mais frequentemente nos equipamentos para a infância e juventude $(41,2 \%)$. Nos equipamentos de saúde e naqueles que se destinam ao desporto e à cultura predomina a intervenção directa, cabendo a esta forma de participação $58,3 \%$ e $41,6 \%$, respectivamente.

$\mathrm{Na}$ intervenção junto dos equipamentos sociais, a Coligação Democrática Eleitoral (CDU) ${ }^{6}$ privilegia a parceria $(36,3 \%)$ e o subsídio $(35,0 \%)$. O Partido Socialista (PS) dá mais atenção à intervenção directa $(38,8 \%)$ e o Partido Social Democrata (PSD) reparte-se pela promoção própria $(40,4 \%)$ e pela utilização do subsídio $(40,4 \%)$.

A actuação dos partidos também se altera em função do domínio social ao qual os equipamentos se destinam. O PS e a CDU actuam mais frequentemente em parceria junto dos equipamentos para idosos; contrariamente, o PSD prefere geri-los sozinho. A CDU privilegia a atribuição de subsídios às entidades que gerem os equipamentos, que se destinam à infância e juventude. O PS reparte-se, quase equitativamente, pelas três modalidades de intervenção e o PSD dá mais atenção à intervenção própria e ao subsídio. Na cultura e desporto, os partidos de esquerda chamam a si a gestão dos equipamentos, contrariamente ao PSD que opta por atribuir subsídios.

Nas acções, a maior parte das 6154 iniciativas recenseadas, relacionadas com a infância e juventude (2644), os idosos (2073) e a saúde (1428), são subsidiadas (47,7 \%), actuação que é comum a todos os partidos (Quadro II). Todavia, nas acções relacionadas com a saúde, a parceria ganha maior relevo na actuação de todas as forças partidárias e o PSD substitui o subsídio pela intervenção como único promotor.

Analisámos a intervenção das freguesias através das actividades que desenvolvem, no plano das acções e da sua participação na gestão de equipamentos sociais, tendo em conta o modo de gestão adoptado. Mas, podemos também examinar as freguesias pela forma de gestão que utilizam.

Das 179 freguesias que responderam ao inquérito, 173 promovem iniciativas próprias, 170 recorrem ao subsídio e 141 actuam em parceria (Quadro III). O recurso à parceria generalizou-se. Apesar de ser a forma de gestão menos utilizada, é comum a 78,8\% das freguesias da AML.

A CDU, embora dando mais atenção à promoção de iniciativas próprias e à atribuição de subsídios, não descora a participação em parceria que é utilizada por $89,3 \%$ das autarquias que dirige, apresentando-se como a força política que mais recorre a esta forma de gestão.

\footnotetext{
6 Trata-se de uma coligação eleitoral constituída pelo Partido Comunista Português, Partido Ecologista «os Verdes»e Independentes.
} 
QUADRO II - Acções em que as freguesias participam segundo o modo de intervenção e o partido político do presidente, por sector social

TABLE II-Activities in which the parishes participate according to type of intervention and the president's political party, as per social sector

\begin{tabular}{|c|c|c|c|c|c|c|c|c|c|c|c|c|c|c|c|c|c|}
\hline & \multicolumn{4}{|c|}{ Idosos } & \multicolumn{4}{|c|}{ Infância e Juventude } & \multicolumn{4}{|c|}{ Saúde } & \multicolumn{4}{|c|}{ Total } \\
\hline & & Pro & Par & Sub & Tot & Pro & Par & Sub & Tot & Pro & Par & Sub & Tot & Pro & Par & Sub & Tot \\
\hline \multirow[t]{2}{*}{$\mathrm{CDU}$} & & 264 & 182 & & 1031 & 386 & 337 & 619 & 1342 & 193 & 271 & 272 & 736 & 843 & 790 & 1476 & 3109 \\
\hline & & 25.6 & 17.7 & 56.7 & & 28.8 & 25.1 & 6.1 & & 26.2 & 36.8 & 37.0 & & 27.1 & 25.4 & 47.5 & \\
\hline \multirow[t]{2}{*}{ PS } & Acções & 271 & 156 & 423 & 850 & 359 & 207 & 459 & 1025 & 150 & 147 & 219 & 516 & 780 & 510 & 1101 & 2391 \\
\hline & & 31.9 & 18.4 & 49.8 & & 35.0 & 20.2 & 44.8 & & 29.1 & 28.5 & 42.4 & & 32.6 & 21.3 & 46.0 & \\
\hline \multirow[t]{2}{*}{ PSD } & Acções & 43 & 17 & & 192 & 60 & & & 277 & & 45 & & 176 & 170 & 120 & 355 & 645 \\
\hline & & 22.4 & 8.9 & 68. & & 21.7 & 20.9 & & & 38.1 & 25.6 & 36.4 & & 26.4 & 18.6 & 55.0 & \\
\hline \multirow[t]{2}{*}{ Total } & Acções & 578 & 355 & 1140 & 2073 & 805 & 602 & 1237 & 2644 & 410 & 463 & 555 & 1428 & 1793 & 1420 & 2932 & 6145 \\
\hline & & 27.9 & 17.1 & 55.0 & & 30.4 & 22.8 & 46.8 & & 28.7 & 32.4 & 38.9 & & 29.2 & 23.1 & 47.7 & \\
\hline
\end{tabular}

(Pro = único promotor; Par = intervenção em parceria; Sub = através de subsídio; Tot $=$ total $)$

Fonte: Inquérito realizado às freguesias no âmbito do Projecto de Investigação n. ${ }^{\circ}$ SSPS/C/PCL/2608/96 - Poder Local e Políticas Sociais: subsidiariedade e parceria na segurança social, 1996-1998 (Silva, 1998)

O PS utiliza muito frequentemente a intervenção própria e recorre com grande intensidade à atribuição de subsídios e utiliza a parceria com menos frequência do que a CDU. Contudo, 70,3 \% das freguesias que dirige celebram acordos com outras instituições para gerir equipamentos ou desenvolver acções no plano social.

QUADRO III - Intervenção das freguesias por modo de participação e partido político

TABLE III - Parish participation according to type of participation, per political party

\begin{tabular}{|l|c|c|c|c|c|c|c|}
\hline \multirow{2}{*}{ Partido } & \multicolumn{2}{|c|}{ Único promotor } & \multicolumn{2}{c|}{ Em parceria } & \multicolumn{2}{c|}{ Através subsídio } & Freguesias \\
\cline { 2 - 7 } inquiridas
\end{tabular}

Fonte: Inquérito realizado às freguesias no âmbito do Projecto de Investigação n. ${ }^{\circ}$ SSPS/C/PCL/2608/96 - Poder Local e Políticas Sociais: subsidiariedade e parceria na segurança social, 1996-1998 (Silva, 1998)

O PSD é o partido que menos recorre à parceria. Parece orientado para a prática do subsídio e dá grande atenção à administração directa, não se afastando muito das restantes forças partidárias na sua utilização. 
Agregando as freguesias de acordo com a sua semelhança, obtivemos os mapas das figuras 1 e 2 , consoante se trate da intervenção junto dos equipamentos ou das acções que promovem. Da sua leitura, concluímos que as freguesias do concelho de Sesimbra adoptam uma política, relativamente aos equipamentos sociais, muito intervencionista ${ }^{7}$, actuando como únicos promotores em $60 \%$ das situações. Azambuja, Mafra e Alcochete mantêm uma forte intervenção própria, recorrendo frequentemente ao subsídio, e Lisboa e Barreiro, apesar da administração directa ter a primazia, distribuem quase equitativamente a sua participação pelas três formas de actuação (Fig. 1). As freguesias mais cooperantes pertencem aos municípios de Amadora, Cascais, Almada e Seixal, onde a parceria assume a principal forma de actuação, e da Moita, que se reparte pela parceria e pela intervenção directa, cabendo a cada uma delas $50 \%$. Por sua vez, as freguesias com uma participação mais liberal pertencem aos municípios de Oeiras e Montijo, cuja participação em parceria é relevante, Palmela, que tem uma elevada intervenção directa, e Sintra, Loures, Vila Franca de Xira e Setúbal que se repartem pelos três modos de actuação.

Relativamente às acções, a intervenção do tipo liberal ganha mais relevância. Com efeito, as freguesias de seis municípios (Sintra, Barreiro, Montijo, Palmela, Sesimbra e Setúbal) participam através de subsídio em mais de $55 \%$ das acções de carácter social. O subsídio é também a principal forma de intervenção das freguesias de Loures, Vila Franca de Xira e Almada, municípios onde a intervenção em parceria tem algum significado e na Azambuja, Moita e Mafra, onde tem relevo a intervenção directa (Fig. 2).

Lisboa e Alcochete adoptam uma política mais intervencionista, com a promoção directa a assumir-se em Lisboa como a principal forma de participação. Por sua vez, Oeiras e Seixal dão mais importância à parceria, se bem que o subsídio seja mais relevante e, finalmente, Cascais e Amadora têm uma política cooperante, constituindo-se nos únicos municípios em que a parceria é o modo de actuação mais comum.

Mas, a característica mais interessante no comportamento das freguesias é a sua dissemelhança relativamente ao modo como intervêm nos equipamentos e nas acções. A figura $3^{8}$ mostra a proximidade/afastamento entre a estrutura de intervenção das freguesias, agregadas por município, no que respeita à intervenção junto dos equipamentos e nas acções em que participam, evidenciando

7 Consoante recorram mais a cada uma das formas de actuação já identificadas classificamos a política das freguesias de intervencionista, cooperante ou liberal. Intervencionista se utilizam com mais frequência a administração directa dos equipamentos sociais ou promovem iniciativas próprias; cooperante se recorrem mais vezes à celebração de parcerias; liberal se a sua participação se faz, na maior parte das situações, através da atribuição de subsídios.

8 A taxonomia representada na figura mede a distância euclidiana entre a estrutura de intervenção das freguesias, agregadas por município. Foi utilizado o programa Statistica, versão 5.0 e a ligação entre as unidades de análise estabelecida por complete linkage. 


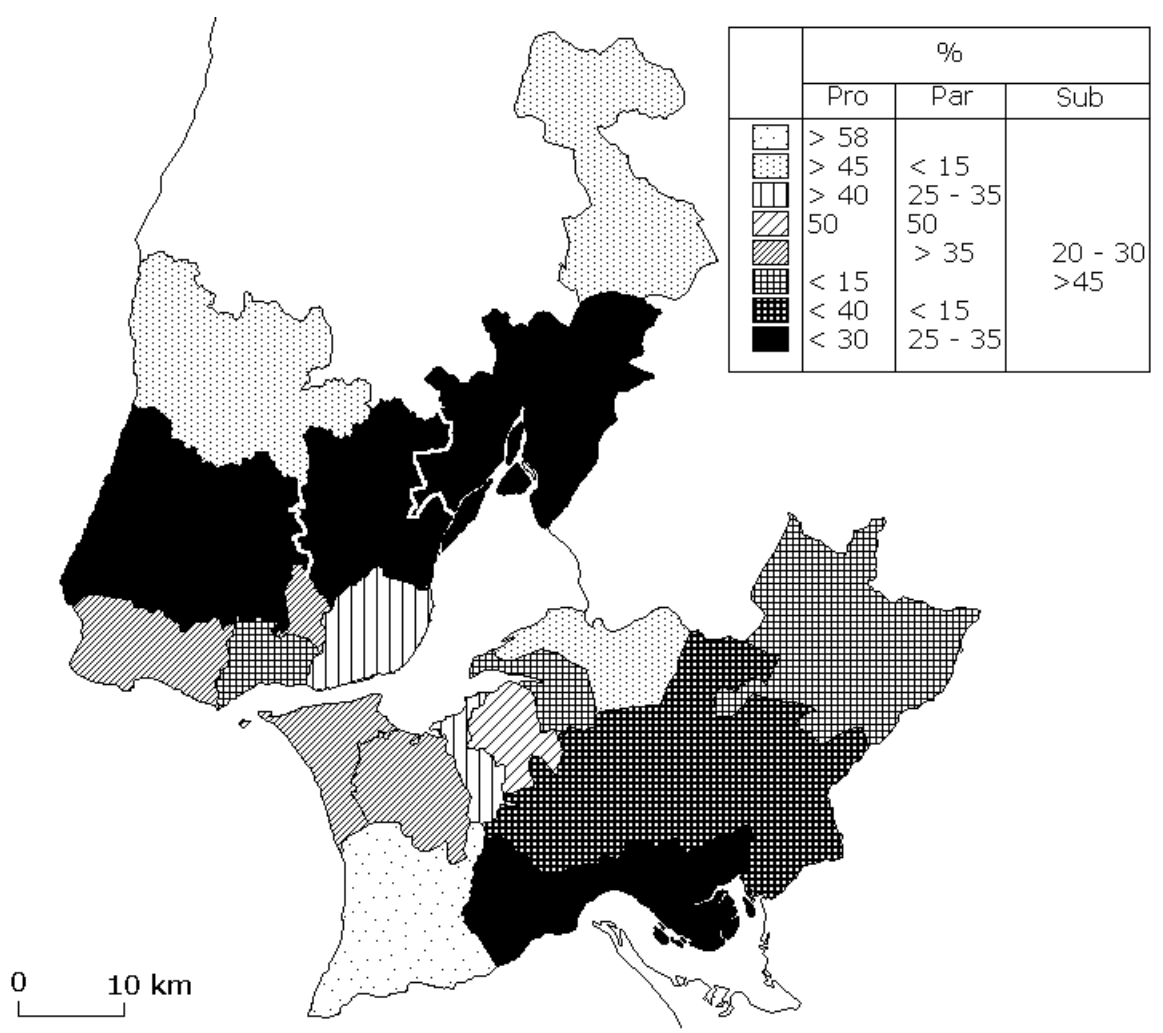

FIG. 1 - Formas de intervenção das freguesias nos equipamentos sociais, por município

FIG. 1 - Use of social amenities by the parishes, as per municipality

$($ Pro $=$ único promotor; Par $=$ intervenção em parceria; $\mathrm{Sub}=$ através de subsídio $)$

Fonte: Inquérito realizado às freguesias no âmbito do Projecto de Investigação n. ${ }^{\circ}$ SSPS/C/PCL/2608/96 - Poder Local e Políticas Sociais: subsidiariedade e parceria na segurança social, 1996-1998 (Silva, 1998)

que as freguesias de cada município actuam de forma diferente consoante se trate de intervir nos equipamentos ou nas acções.

A avaliar pela proximidade da estrutura de participação nos equipamentos e nas acções, apenas em dois municípios (Oeiras e Loures) a intervenção das freguesias mostra um certo grau de coerência.

De facto, há uma diversidade de factores que actuam à escala local influenciando as políticas sociais adoptadas pelas freguesias, dos quais destacamos: a composição social e etária da população que geram procuras diferenciadas, a 
35

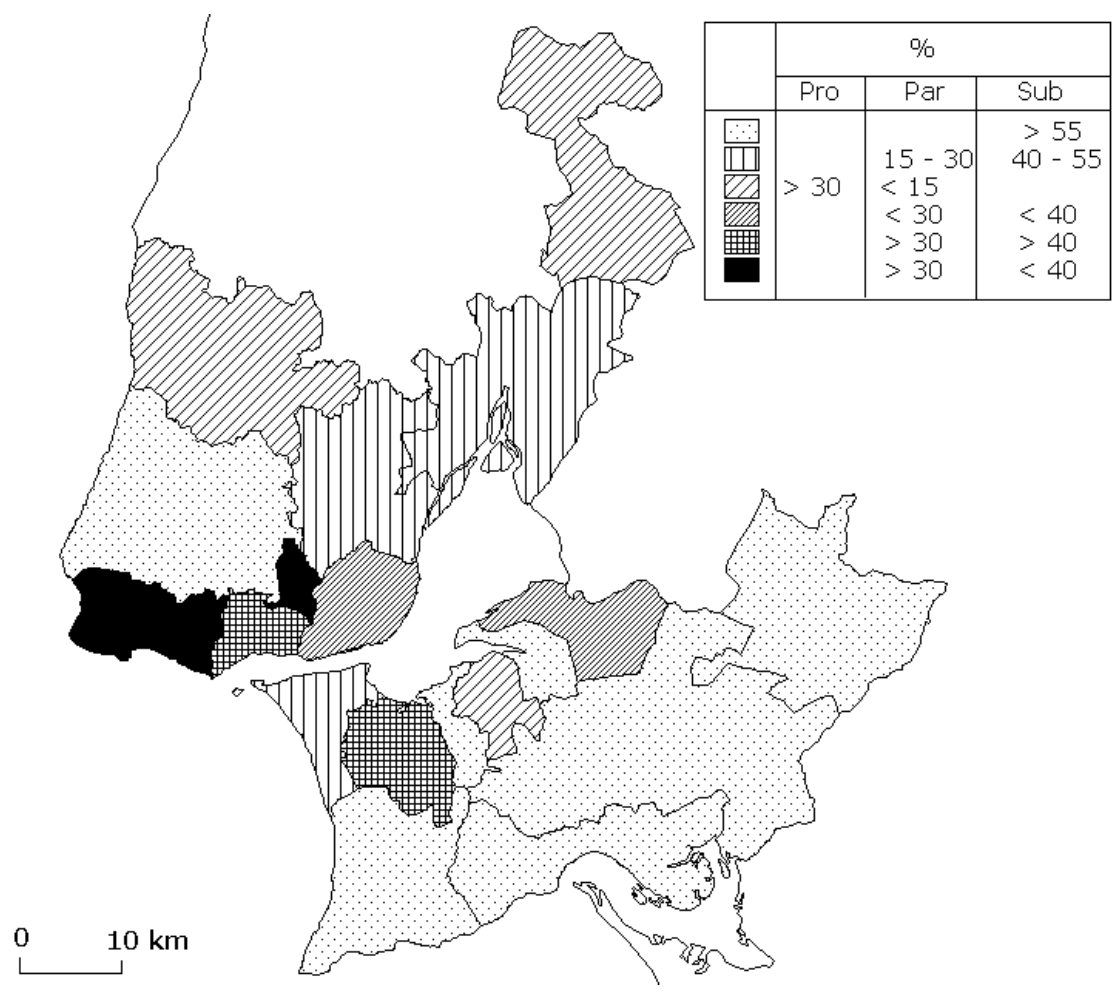

FIG. 2 - Formas de intervenção das freguesias nas acções, iniciativas e projectos de carácter social, por município

FIG. 2 - Parish participation in social activities, plans and projects, as per Municipality

(Pro = único promotor; Par = intervenção em parceria; Sub = através de subsídio)

Fonte: Inquérito realizado às freguesias no âmbito do Projecto de Investigação n. ${ }^{\circ}$ SSPS/C/PCL/2608/96 - Poder Local e Políticas Sociais: subsidiariedade e parceria na segurança social, 1996-1998 (Silva, 1998)

dinâmica dos eleitos, a capacidade reivindicativa e organizativa das populações, a disponibilidade financeira de que dispõem, a delegação de competências do município, a opção de gestão mais liberal ou intervencionista que perfilham, a composição política dos seus órgãos.

Esta multiplicidade de factores gera uma grande variedade de actuações das freguesias. Procurando agrupá-las de acordo com a semelhança das políticas sociais que adoptam, tendo por base a actuação junto dos equipamentos e o modo como desenvolvem as acções e as iniciativas em que participam, elaborámos o mapa da figura 4, no qual podemos observar que o padrão das políticas sociais é um mosaico, em que as freguesias que desenvolvem uma política social semelhante se pulverizam por toda a região. 


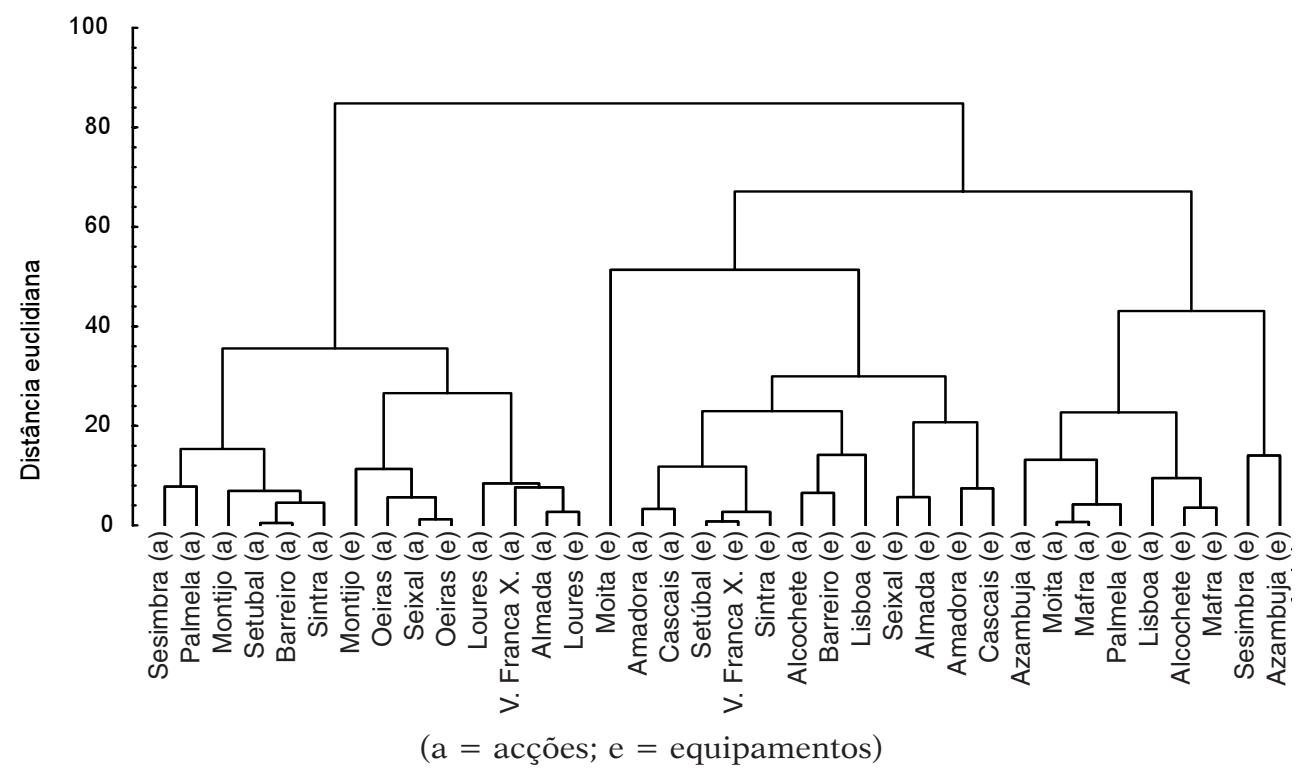

FIG. 3 - Proximidade entre os municípios a partir da estrutura do envolvimento das freguesias nos equipamentos e em acções, iniciativas e projectos de carácter social

FIG. 3 - Proximity between municipalities in relation to parish involvement in the amenities, activities, plans and projects of a social character

Fonte: Inquérito realizado às freguesias no âmbito do Projecto de Investigação n. ${ }^{\circ}$ SSPS/C/PCL/2608/96 - Poder Local e Políticas Sociais: subsidiariedade e parceria na segurança social, 1996-1998 (Silva, 1998)

Todavia, é nítida a influência do município em que se integram. Com efeito, em vários municípios há um conjunto maioritário de freguesias que pertencem ao mesmo grupo, como é o caso de Palmela, Seixal e Setúbal, relativamente ao grupo I, Loures, Oeiras, Vila Franca de Xira, Barreiro e Sesimbra, ao grupo III e Azambuja, Mafra, Sintra e Moita, ao grupo V.

\section{Os parceiros das freguesias}

A parceria, apesar de alguns autores a considerarem ser recente entre nós ${ }^{9}$, generalizou-se na actividade das freguesias da AML. A sua utilização pode

9 Rodrigues E Stoer (1998: 6) datam as primeiras experiências de projectos de desenvolvimento local em parceria nos anos 60. No entanto, é com a entrada de Portugal na Comunidade Económica Europeia, em 1986, que se generaliza o recurso à parceria. Para uma visão $\mathrm{m}$ a i

alargada, ver RodRIGUeS E STOER (1998: 5 a 10). Não obstante, importa ter em consideração que a parceria público-privado, entendida em sentido lato, é uma forma de implementação muito antiga 


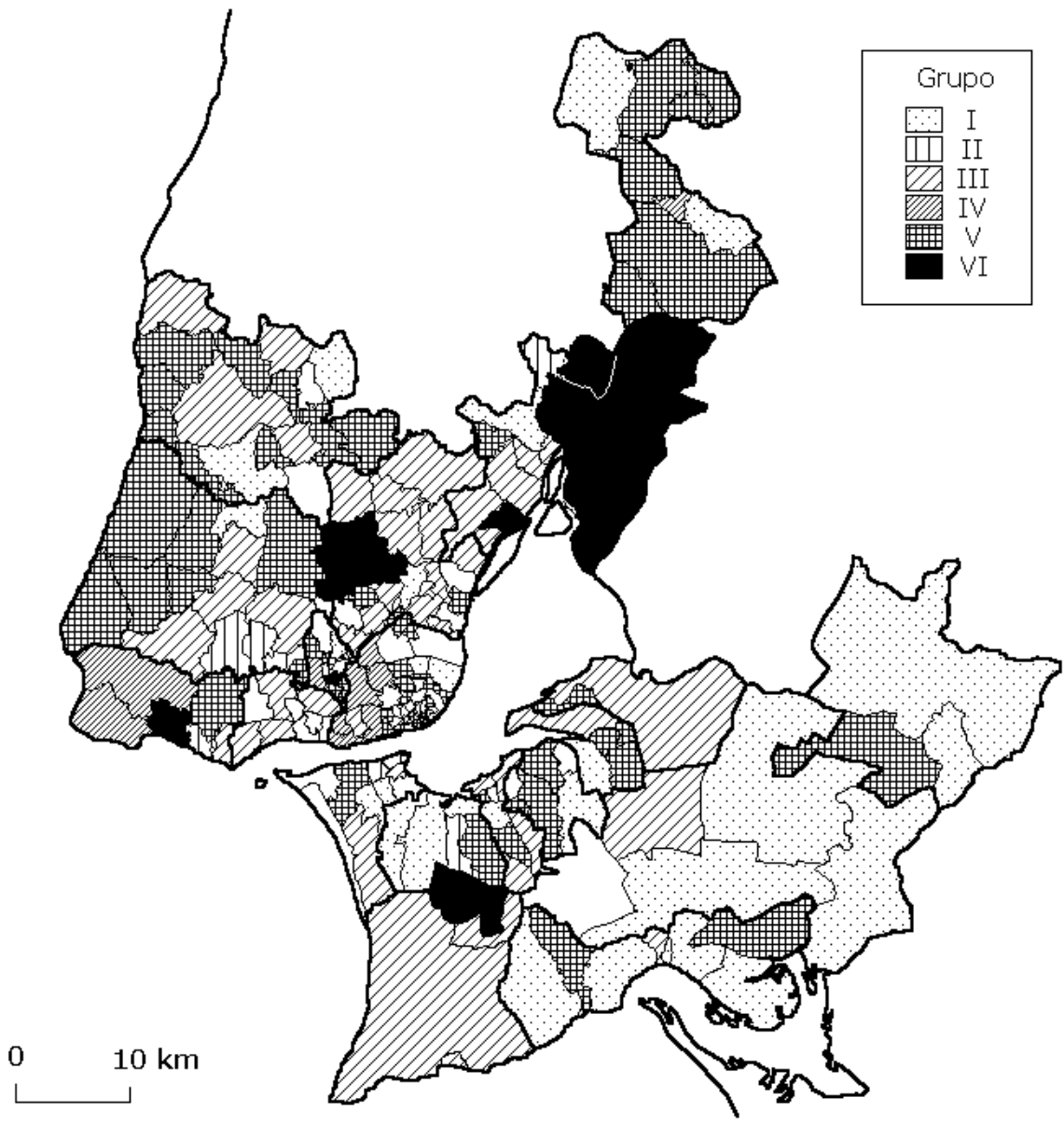

FIG. 4 - Diferenciação geográfica das políticas sociais das freguesias da AML FIG. 4 - Geographic differentiation of social policies of Lisbon Metropolitan Area parishes

Fonte: Inquérito realizado às freguesias no âmbito do Projecto de Investigação n. ${ }^{\circ}$ SSPS/C/PCL/2608/96 - Poder Local e Políticas Sociais: subsidiariedade e parceria na segurança social, 1996-1998 (Silva, 1998)

revestir-se de acordos celebrados formalmente ou não, se bem que a informalidade parece ter a preferência.

Tendo-se generalizado, importa conhecer quem são os parceiros que conjuntamente com as freguesias actuam na regulação à escala local e se se mantêm ou alteram em função da área social para que são constituídas as parcerias e do partido maioritário na freguesia que as celebra.

Os parceiros, que mais frequentemente aparecem associados às freguesias, para cada uma das áreas sociais aqui tratadas (idosos, infância e juventude 
e saúde) são, basicamente, os mesmos com pequenas alterações que têm a ver com a especificidade da área respectiva.

Nas actividades destinadas aos idosos, as freguesias escolhem como parceiros, mais frequentemente, as Associações de Reformados, Pensionistas e Idosos e os Centros Paroquiais, mas também as Colectividades, os Bombeiros, as Misericórdias, organismos da Segurança Social e as IPSS. Nas iniciativas que se dirigem à infância e à juventude, as freguesias associam-se às colectividades e às escolas e têm relevância, ainda, as parcerias com os Centros Paroquiais, as Associações de Pais e de Jovens, os Bombeiros, as Associações de Estudantes e as IPSS. Finalmente, na área da saúde, as freguesias preferem fazer acordos com os Bombeiros e com organismos da Administração Central (Serviços de Saúde, Escolas, Serviços de Segurança Social), com Associações de Reformados e, também, com instituições ligadas à Igreja (Misericórdia e Centros Paroquiais) e IPSS.

As escolhas dos parceiros pelas freguesias, tendo em consideração o partido político, afastam-se quando se trata dos idosos e aproximam-se bastante nas restantes áreas sociais. A CDU, nas acções com os idosos, prefere ter como parceiros, nas três primeiras opções, as Associações de Reformados, as Colectividades e os Centros Paroquiais. O PS e o PSD têm a mesma opção nas duas primeiras (Centros Paroquiais e Bombeiros) e como terceira escolha têm, respectivamente, as Associações de Reformados e as Câmaras Municipais (Quadro IV).

Note-se que a quarta opção do PSD recai nos Grupos de Voluntariado Social, que correspondem à décima primeira opção do PS e à décima terceira da CDU.

Nas áreas da infância e juventude e saúde, todas as forças políticas coincidem nas três primeiras opções. No primeiro caso, são seleccionadas as Colectividades, Escolas e Centros Paroquiais e, no segundo, Bombeiros, Serviços de Saúde e Escolas.

A generalização do recurso a parcerias entre as freguesias e outras instituições é confirmado pelas organizações públicas e entidades particulares sem fins lucrativos. Com efeito, todas as organizações entrevistadas ${ }^{10}$ concordam com a celebração de acordos de cooperação com o objectivo de desenvolver acções ou gerir equipamentos, reconhecendo existirem vantagens mútuas neste tipo de actuação, e 58,3\% têm ou tiveram parcerias com as freguesias.

Note-se, ainda, que dez das doze instituições entrevistadas afirmaram ter recebido subsídios das juntas de freguesia que, cada vez com mais frequência,

das políticas públicas.

10 Foram entrevistadas, no âmbito da dissertação de mestrado já referida, 12 entidades de diferente estatuto (colectividades, associações de idosos, centros de saúde, associações de apoio à infância e uma misericórdia) que desenvolvem actividades relacionadas com diversos sectores da população e áreas do domínio social (crianças, jovens, idosos, deficientes, saúde, cultura e 
QUADRO IV - Parceiros das freguesias por área social e partido político

TABLE IV-Parish partnerships per social sector and political party

\begin{tabular}{|c|c|c|c|c|c|c|c|c|c|c|c|}
\hline Parceiros & $\mathrm{CDU}$ & PS & PSD & Parceiros & $\mathrm{CDU}$ & PS & PSD & Parceiros & $\mathrm{CDU}$ & PS & PSD \\
\hline Misericórdia & 8.7 & 7.7 & 8.6 & Misericórdia & 3.4 & 2.6 & 3.6 & Misericórdia & 6.5 & 5.1 & 1.9 \\
\hline Cooperativas & 8.0 & 1.0 & 1.2 & Cooperativas & 1.8 & 1.3 & 0.7 & Cooperativas & 3.2 & 1.9 & 0.0 \\
\hline Colectividades & 13.6 & 8.4 & 8.6 & Colectividades & 13.1 & 13.8 & 14.5 & Colectividades & 3.9 & 3.2 & 0.0 \\
\hline Ass Reform/Idosos & 14.3 & 11.7 & 9.9 & Centros Paroquiais & 7.9 & 9.7 & 10.1 & Ass Reform/Idosos & 7.9 & 3.8 & 1.9 \\
\hline Centros Paroquiais & 9.6 & 13.0 & 12.3 & Ass Jovens & 6.7 & 6.2 & 4.3 & Centros Paroquiais & 4.7 & 3.8 & 3.8 \\
\hline Grupos Volun Social & 2.3 & 4.0 & 9.9 & Ass Estudantes & 6.5 & 4.8 & 3.6 & Ass Jovens & 3.2 & 0.6 & 1.9 \\
\hline Fundações & 0.5 & 0.3 & 1.2 & Grupos Volun Social & 3.0 & 2.9 & 5.1 & Grupos Volun Social & 2.5 & 4.4 & 1.9 \\
\hline Bombeiros & 5.9 & 12.4 & 12.3 & Fundações & 0.5 & 0.0 & 0.0 & Fundações & 0.7 & 0.0 & 0.0 \\
\hline Ass/Com Moradores & 3.0 & 3.0 & 1.2 & Bombeiros & 5.5 & 6.2 & 6.5 & Bombeiros & 11.1 & 19.0 & 28.3 \\
\hline Outras IPSS & 5.6 & 5.7 & 3.7 & Associações de Pais & 7.4 & 5.5 & 6.5 & Ass Pais & 3.9 & 4.4 & 0.0 \\
\hline Outras Asso/ONG & 1.9 & 3.0 & 3.7 & Ass/Com Moradores & 4.4 & 2.6 & 2.9 & Ass/Com Moradores & 3.6 & 1.3 & 0.0 \\
\hline Cruz Vermelha & 0.7 & 0.7 & 3.7 & Outras IPSS & 4.7 & 3.7 & 3.6 & Outras IPSS & 4.7 & 3.8 & 5.7 \\
\hline Junta de Freguesia & 0.9 & 0.7 & 0.0 & Outras Ass/ONG & 1.3 & 1.8 & 2.2 & Outras Ass/ONG & 2.5 & 1.9 & 1.9 \\
\hline Serviços Saúde & 4.0 & 8.0 & 4.9 & Junta de Freguesia & 0.3 & 0.7 & 0.7 & Ass Deficientes & 0.4 & 0.6 & 0.0 \\
\hline Serv Segur Social & 8.4 & 7.0 & 6.2 & Serviços Saúde & 2.0 & 3.3 & 2.9 & Cruz Vermelha & 0.4 & 1.3 & 3.8 \\
\hline Escolas & 5.6 & 5.0 & 0.0 & Serv Segur Social & 3.5 & 4.0 & 2.9 & Serviços Saúde & 11.1 & 17.7 & 13.2 \\
\hline Centro de Emprego & 2.3 & 2.3 & 0.0 & Escolas & 11.2 & 11.6 & 13.0 & Serv Segur Social & 6.1 & 6.3 & 3.8 \\
\hline Centro Form Profi & 0.7 & 0.3 & 0.0 & Delegação Escolar & 4.2 & 3.3 & 3.6 & Escolas & 9.3 & 8.2 & 13.2 \\
\hline Grupos de Jovens & 0.0 & 0.7 & 0.0 & Equipa Ens Especial & 4.4 & 2.2 & 4.3 & Delegação Escolar & 1.8 & 1.9 & 0.0 \\
\hline \multirow[t]{10}{*}{ Câmara Municipal } & 4.0 & 5.0 & 12.3 & Centro de Emprego & 3.4 & 4.4 & 1.4 & Equipa Ens Especial & 2.2 & 1.9 & 3.8 \\
\hline & 100 & 100 & 100 & Centro Form Profi & 1.8 & 2.4 & 0.7 & Centro de Emprego & 2.9 & 2.5 & 1.9 \\
\hline & & & & Secretar Estado Juv & 0.3 & 2.4 & 0.0 & Centro Form Profi & 1.8 & 0.0 & 0.0 \\
\hline & & & & Câmara Municipal & 2.5 & 4.4 & 6.5 & Tribunal & 0.4 & 0.0 & 3.8 \\
\hline & & & & Casa do Povo & 0.0 & 0.2 & 0.0 & GNR/PSP & 2.9 & 3.8 & 7.5 \\
\hline & & & & & 100 & 100 & 100 & Ass Carácter n/ Soc. & 1.4 & 0.6 & 0.0 \\
\hline & & & & & & & & Junta de Turismo & 0.7 & 0.6 & 1.9 \\
\hline & & & & & & & & Grup. Dador Sangue & 0.0 & 0.6 & 0.0 \\
\hline & & & & & & & & Câmara Municipal & 0.4 & 0.6 & 0.0 \\
\hline & & & & & & & & & 100 & 100 & 100 \\
\hline
\end{tabular}

(Fonte: Inquérito realizado às freguesias no âmbito do Projecto de Investigação n. ${ }^{\circ}$ SSPS/C/PCL/2608/96 - Poder Local e Políticas Sociais: subsidiariedade e parceria na segurança social, 1996-1998 (Silva, 1998)

são atribuídos em função das actividades que desenvolvem ou tendo em vista uma iniciativa específica. Neste último caso, o subsídio confunde-se com a parceria.

Registe-se, ainda, que as organizações contactadas defendem que os municípios e as freguesias deveriam ter mais competências e meios porque «quando o poder está mais próximo os problemas resolvem-se muito mais rapidamente» (Confederação Nacional de Reformados, Pensionistas e Idosos-MURPI), ou porque "as autarquias estão mais próximas das populações pelo que conhecem melhor os problemas» (Associação Portuguesa de Deficientes - APD). Havendo, também, quem admita que "as freguesias e os municípios fazem mais com menos 
dinheiro» (Associação das Iniciativas Populares para a Infância do Concelho de Almada - AIPICA) e quem critique o Governo por investir em "gabinetes que nada fazem quando esse dinheiro poderia ter muito melhor uso» (União Pensionistas da Previdência e Segurança Social - UPPSS).

Em suma, identificámos três tipos de organizações com as quais as freguesias estabelecem acordos de parceria: aquelas que mantêm uma estreita ligação à Igreja (Misericórdias, Centros Sociais e Paroquiais, Grupos de Voluntariado Social e algumas IPSS), as que dependem de outros níveis da Administração (Escolas, Serviços de Segurança Social, Centros de Saúde, etc.) e as organizações da sociedade civil (Associações de Reformados, de Pais, de Jovens, de Estudantes, colectividades, Bombeiros, etc.).

Apesar de não existirem grandes diferenças na escolha dos parceiros das freguesias em função partido político, registe-se que o PCP e seus aliados celebram mais facilmente acordos com as organizações da sociedade civil e organismos de outros níveis da Administração. O PS tem um comportamento idêntico, se bem que dá mais relevo às organizações ligadas à Igreja e o PSD é o partido que mais acordos celebra com instituições ligadas à Igreja.

Finalmente, podemos afirmar que uma parte do poder das freguesias é descentralizado para as organizações da sociedade civil, que actuam na sua área geográfica, através dos subsídios que concedem ou das parcerias que entre ambas se estabelecem, confirmando que estas organizações participam, conjuntamente com aquelas, na regulação social na escala local.

\section{NOTA FINAL}

As recentes alterações que ocorreram nos recursos financeiros das freguesias ${ }^{11}$, no grau e características da descentralização e o volume e o tipo de relações que as freguesias mantêm com organizações de carácter social, para as quais descentralizam parte das suas competências, indicia que se poderá estar a operar a substituição do modo de regulação fordista, que se encontra associado a um modelo de desenvolvimento centralizado, que atribui pouca importância às freguesias, para um outro mais descentralizado, em que as freguesias assumem maior importância e em que existe uma efectiva partilha de respon-sa-bilidades entre o sector público e as organizações da sociedade civil.

A generalização de acordos de parceria, celebrados entre as juntas de freguesia e instituições públicas e entidades particulares, mostra que a descentralização, que se está a operar, incorpora elementos da sociedade civil e contribui para encorajar a formação de grupos que se interessam pelos problemas locais. Deste modo, saem reforçadas as redes sociais internas de resi- 
dentes e promove-se a autonomia das populações, garante-se a sua participação, individualmente ou através das suas organizações, na resolução de muitos problemas sociais e na construção do seu próprio futuro, contribuindo para o reforço da democracia.

O papel e a actividade das freguesias têm de ser vistos numa perspectiva integrada no território, ou seja, as opções e deliberações tomadas pelas freguesias e a sua actuação são influenciadas e, até certo ponto, condicionadas pelas características económicas, sociais, culturais e políticas da sua área geográfica, pela natureza rural ou urbana do lugar, pela composição política dos seus órgãos e pelas relações que se estabelecem entre as pessoas que vivem e de algum modo actuam num dado espaço, consideradas individualmente ou através das suas organizações.

Podemos, por isso, concluir que múltiplos factores actuam à escala local influenciando as políticas sociais adoptadas pelas freguesias, de entre os quais destacamos: a composição social e etária da população, que gera procuras diferenciadas, as características do tecido económico, a dinâmica dos eleitos, a capacidade organizativa e reivindicativa das populações, a disponibilidade financeira de que dispõem, o recurso à delegação de competências por parte do município de que fazem parte, a opção de gestão mais liberal ou intervencionista que perfilham e a composição política dos seus órgãos.

A combinação destes factores, em proporções diferentes, em cada uma das freguesias da AML, manifesta-se na grande diversidade de opções que são adoptadas pelos seus órgãos e reflecte-se na diferenciação geográfica das políticas sociais.

\section{BIBLIOGRAFIA}

Amaral, J. F. (1997) - Economia Portuguesa, União Europeia e Globalização. Economia \& Prospectiva. Vol. 1, n. ${ }^{\circ}$ 1, Abr/Jun, Ministério da Economia, Lisboa.

Benko, G. (1996) - Economia Espaço e Globalização na Aurora do Século XXI. Editora Hucitec, São Paulo.

Benko, G.; Lipietz, A. (Organ.) (1994) - As Regiões Ganhadoras, Distritos e Redes os Novos Paradigmas da Geografia Económica. Celta, Oeiras.

Borja, J.; CASTElls, M. (1997) - Local y Global - la gestión de las ciudades en la era de la información. Santillana, S. A. Taurus, Madrid.

Boyer, R. (1994) - As Alternativas ao Fordismo, dos anos 80 ao Século XXI. As Regiões Ganhadoras, Distritos e Redes os Novos Paradigmas da Geografia Económica. Celta, Oeiras.

Constituição da República Portuguesa. 4. ${ }^{a}$ Revisão, INCM, Lisboa, 1997.

Dunford, M.(1994) - Trajectórias Industriais e Relações Sociais. As Regiões Ganhadoras, Distritos e Redes os Novos Paradigmas da Geografia Económica. Celta, Oeiras. 
Friedmann, J. (1996) - Empowerment-uma Política de Desenvolvimento Alternativo. Celta, Oeiras.

Galbraith, J. K. (1997)-A Sociedade Desejável Para um Futuro Mais Seguro e Melhor. Publicações Europa-América, Mem Matins.

Grupo de Lisboa (1994) - Limites à Competição. 2. ' Edição, Publicações Europa-América, Mem Martins.

Kovács, I.; Castillo, J. J. (1998) - Novos Modelos de Produção, Trabalho e Pessoas. Celta Editora, Oeiras.

Lopes, J. S. (1997) - Portugal e a Globalização Europeia. Economia \& Prospectiva. Vol. 1, n. ${ }^{\circ}$ 1, Abr/Jun, Ministério da Economia, Lisboa.

Rodrigues, F. e Stoer, S. (1998) - Entre Parceria e Partenariado. Amigos amigos, negócios à parte. Celta, Oeiras.

Silva, C. N. (1995) - Poder Local e Território, Análise Geográfica das Políticas Municipais, 19741994. Dissertação de doutoramento, policopiado.

Silva, C. N. (Coord.) (1998) - Poder Local e Políticas Sociais em Portugal. Subsidiariedade e parceria na segurança social. Projecto SSPS/S/PCL/2608/96 - Relatório Final, Junho de 1998. (Vol. 1 - Relatório de Investigação, 1998, 316 pág.).

11 A receita das freguesias, em 1997, a preços constantes, foi superior em $50 \%$ à de 1993. 